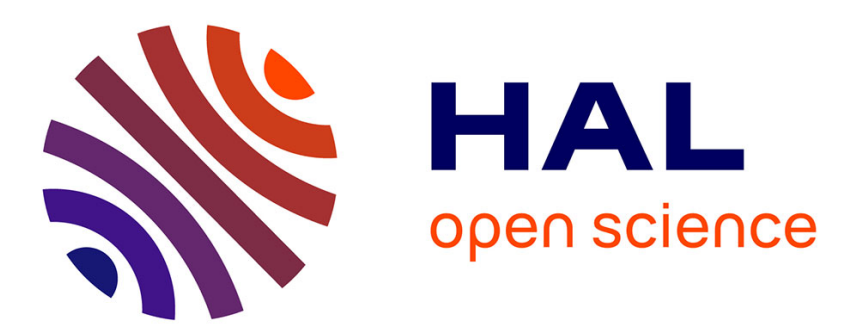

\title{
Activités antifongiques de la sirodesmine PL et de deux analogues naturels isolés de Phoma lingam (Tode) Desm. Action antagoniste du zinc
}

\author{
Bertrand Poiret, Albert Kollmann, Jean-François Bousquet
}

\section{To cite this version:}

Bertrand Poiret, Albert Kollmann, Jean-François Bousquet. Activités antifongiques de la sirodesmine PL et de deux analogues naturels isolés de Phoma lingam (Tode) Desm. Action antagoniste du zinc. Agronomie, 1985, 5 (6), pp.533-538. hal-00884782

\section{HAL Id: hal-00884782 https://hal.science/hal-00884782}

Submitted on 1 Jan 1985

HAL is a multi-disciplinary open access archive for the deposit and dissemination of scientific research documents, whether they are published or not. The documents may come from teaching and research institutions in France or abroad, or from public or private research centers.
L'archive ouverte pluridisciplinaire $\mathbf{H A L}$, est destinée au dépôt et à la diffusion de documents scientifiques de niveau recherche, publiés ou non, émanant des établissements d'enseignement et de recherche français ou étrangers, des laboratoires publics ou privés. 


\section{Activités antifongiques de la sirodesmine PL et de deux analogues naturels isolés de Phoma lingam (Tode) Desm. Action antagoniste du zinc}

Bertrand POIRET, Albert KOLLMANN \& Jean-François BOUSQUET

I.N.R.A., Station de Pathologie Végétale, Route de St-Cyr, F 78000 Versailles

RÉSUMÉ

La sirodesmine PL et deux analogues naturels, la désacétylsirodesmine PL et la diacétylsirodesmine PL, isolées de Phoma lingam parasite du colza, présentent des activités antifongiques importantes. Quatre critères d'activité sont étudiés sur 2 parasites ( $S$. nodorum et $B$. cinerea) : croissance linéaire, croissance pondérale, germination des spores et sporulation. Ces 3 épipolythiopipérazinediones réduisent la croissance mycélienne des deux champignons, cependant la désacétylsirodesmine PL inhibe spécifiquement et à basse concentration leur sporulation ; seule la germination des spores de $B$. cinerea est affectée par la sirodesmine PL et la diacétylsirodesmine PL.

L'addition de $\mathrm{Zn}^{++}$au milieu de culture permet d'annuler les effets toxiques au niveau de la sporulation et également, dans certains cas, au niveau de la croissance mycélienne.

Mots clés additionnels : Botrytis cinerea, Septoria nodorum, croissance, germination, sporulation.

Antifungal activity of sirodesmin PL and two natural analogs isolated from Phoma lingam (Tode) Desm. and antagonistic action of $\mathrm{Zn}^{++}$

Sirodesmin PL and two related toxins, desacetylsirodesmin PL and diacetylsirodesmin PL, were isolated from Phoma lingam and showed antifungal activity. The activity of each was tested on two plant pathogens (Septoria nodorum and Botrytis cinerea) for the following parameters : linear growth, dry weight, spore germination and spore production. All three epipolythiopiperazinediones decreased mycelial growth of both fungi. However desacetylsirodesmine PL inhibited spore production in both fungi specifically and at low concentration. The addition of $\mathrm{Zn}^{2+}$ to the culture medium reversed the inhibition of spore production and in some experiments even allowed normal mycelial growth. Under the same conditions, $\mathrm{Fe}^{2+}, \mathrm{Mn}^{2+} \mathrm{and}^{\mathrm{Mg}} \mathrm{Mg}^{2+}$ had no effect.

Additional key words : Botrytis cinerea, Septoria nodorum, growth, germination, sporulation.

\section{INTRODUCTION}

Les sirodesmines appartiennent au groupe des épipolythiopipérazinediones. Dans une revue générale sur ces produits, TAYLOR (1971) rapporte leurs propriétés biologiques et signale en particulier les effets inhibiteurs de la gliotoxine sur certains champignons; à notre connaissance, cependant, les activités antifongi- ques des sirodesmines PL, notamment sur la sporulation des micromycètes, n'ont pas été signalées.

Les propriétés phytotoxiques de la désacétylsirodesmine PL et de la sirodesmine PL isolées de Phoma lingam (Tode) Desm. ont été décrites par BOUSQUET et al. (1977) et leurs structures respectives établies par FEREZOU et al. (1977).

Nous avons isolé de la même espèce fongique un 
nouvel analogue naturel, déterminé puis synthétisé par FEREZOU (comm. pers., 1982), l'acétyl-6-sirodesmine PL, que nous nommerons diacétylsirodesmine PL.

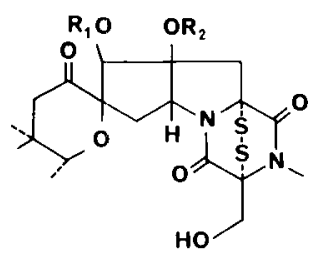

Sirodesmine PL : $\mathrm{R}_{1}=-\mathrm{CO}-\mathrm{CH}_{3}, \mathrm{R}_{2}=\mathrm{H}$ Désacétylsirodesmine PL : $\mathrm{R}_{1}=\mathrm{H}, \mathrm{R}_{2}=\mathrm{H}$ Diacétylsirodesmine $\mathrm{PL}: \mathrm{R}_{1}=-\mathrm{CO}-\mathrm{CH}_{3}$, $\mathrm{R}_{2}=-\mathrm{CO}-\mathrm{CH}_{3}$.

Notre étude porte sur l'activité antifongique de chacun de ces 3 composés, vis-à-vis de 2 champignons : Septoria nodorum Berk. et Botrytis cinerea Pers. Cette activité est évaluée sur la croissance linéaire et la sporulation en milieu gélosé, sur la croissance pondérale en milieu liquide et enfin sur la germination des spores. Tous nos essais ont été réalisés avec les molécules purifiées cristallisées.

L'utilisation comparative dans le milieu de culture de 2 extraits de malt d'origines commerciales différentes nous a permis fortuitement de constater une action antagoniste $\mathrm{du} \mathrm{Zn}^{++}$(B. POIRET, résult. non publiés, 1983). Cet antagonisme est étudié sur la croissance linéaire et la sporulation des 2 champignons.

\section{MATÉRIEL ET MÉTHODES}

\section{A. Obtention des sirodesmines}

Les sirodesmines PL sont obtenues à partir de cultures de $P$. lingam selon les techniques décrites par BOUSQUET et al. (1977).

121 de culture fournissent environ $5 \mathrm{~g}$ de sirodesmine PL, $150 \mathrm{mg}$ de diacétylsirodesmine PL et $200 \mathrm{mg}$ de désacétylsirodesmine PL. Les 3 composés sont caractérisés en CCM (MERCK, DC Plastikfolien Kieselgel $60 \mathrm{~F} 2540,2 \mathrm{~mm}$ ) par des $\mathrm{Rf}$ respectifs de 0,55 ; 0,50 et 0,37 pour les diacétylsirodesmine PL, sirodesmine PL et désacétylsirodesmine PL dans le système d'élution $\mathrm{CHCl}_{3}$ /acétate d'éthyle $1: 1$. Ils sont visibles en UV (254 nm) et se révèlent en jaune après vaporisation d'une solution à $50 \mathrm{p} .100 \mathrm{~d}^{\prime} \mathrm{H}_{2} \mathrm{SO}_{4}$ suivie d'un rapide chauffage à $110^{\circ} \mathrm{C}$. Une purification finale est effectuée par plusieurs recristallisations successives dans l'acétate d'éthyle.

\section{B. Incorporation des sirodesmines}

Les produits sont mis en solution dans du méthanol. Des dilutions sont effectuées de manière à ce que la concentration finale de ce dernier dans le milieu de culture corresponde à 1 p. 100. L'incorporation a lieu après stérilisation. Dans le cas de milieux solides, l'introduction des sirodesmines a lieu stérilement à $50{ }^{\circ} \mathrm{C}$ lorsque le milieu est en surfusion.

Dans toutes nos expériences les résultats sont exprimés en p. 100 du témoin contenant 1 p. 100 de méthanol.

\section{Croissance linéaire}

Les cultures sont effectuées sur milieu gélosé en boîtes de Petri plastique de $10 \mathrm{~cm}$ de diamètre. La croissance linéaire de $B$. cinerea est étudiée sur le milieu suivant : glucose : $10 \mathrm{~g} ; \mathrm{KH}_{2} \mathrm{PO}_{4}: 2 \mathrm{~g} ; \mathrm{K}_{2} \mathrm{HPO}_{4}$ : $1,5 \mathrm{~g} ;\left(\mathrm{NH}_{4}\right)_{2} \mathrm{SO}_{4}: 1 \mathrm{~g} ; \mathrm{Mg} \mathrm{SO}, 7 \mathrm{H}_{2} \mathrm{O}: 0,5 \mathrm{~g}$; extrait de levure : $2 \mathrm{~g}$; gélose : $20 \mathrm{~g}$; eau désionisée q.s.p : $1000 \mathrm{ml}$, à l'obscurité et à $25^{\circ} \mathrm{C}$. Celle de $S$. nodorum sur milieu malt à 2 p. 100 avec 2 p. 100 de gélose (CRISTOMALT DIFAL, 69400 Villefranche/ Saône), à $18{ }^{\circ} \mathrm{C}$, avec une photopériode $16 \mathrm{~h}$ lumière/ 8 h obscurité (éclairage 3000 lux tubes fluorescents Sylvania lifeline et blanc industrie $(1 / 1))$.

On dépose au centre de chaque boîte de Petri un " disque " mycélien calibré de $8 \mathrm{~mm}$ de diamètre, provenant du front de cultures en milieu solide. Les diamètres des colonies sont mesurés quotidiennement; les résultats sont exprimés en p. 100 du témoin.

\section{Croissance pondérale}

La croissance pondérale est mesurée à partir de cultures effectuées dans des fioles de $250 \mathrm{ml}$ contenant $100 \mathrm{ml}$ de milieu liquide.

Chaque fiole est ensemencée par 3 disques mycéliens obtenus comme précédemment (cf. C). Les cultures sont soumises à une agitation de 100 tours/mn et placées à l'obscurité à $20^{\circ} \mathrm{C}$.

Après $7 \mathrm{j}$ de culture pour $S$. nodorum et $5 \mathrm{j}$ pour $B$. cinerea, le mycélium est recueilli sur de la gaze puis lavé à l'eau distillée; le poids de matière sèche est déterminé après lyophilisation. Les résultats sont exprimés en p. 100 du témoin.

\section{E. Germination des spores}

$25 \mathrm{ml}$ d'une suspension de spores dans de l'eau stérile $\left(1,5 \times 10^{5}\right.$ spores $\left./ \mathrm{ml}\right)$ sont incorporés dans $75 \mathrm{ml}$ de milieu malt 2 p. 100 avec 2 p. 100 de gélose contenant les toxines et maintenus en surfusion à $45^{\circ} \mathrm{C}$. Ce mélange, après agitation, est réparti dans 10 boîtes de Petri. La période d'incubation est de $24 \mathrm{~h}$ à la température du laboratoire et à l'obscurité ; cependant cette période est prolongée jusqu'à $36 \mathrm{~h}$ pour $S$. nodorum. Le comptage est fait sur 300 spores prises au hasard dans la masse gélosée pour chaque boîte de Petri. Le critère de germination choisi est l'observation d'un tube germinatif quelle que soit sa taille. Les résultats sont exprimés en p. 100 de spores germées par rapport au témoin.

\section{F. Sporulation}

Les cultures fongiques sont effectuées en boîtes de Petri sur milieu malt à 2 p. 100 avec 2 p. 100 de gélose. Une implantation centrale de mycélium frontal est réalisée pour $B$. cinerea, alors que pour $S$. nodorum les boîtes sont ensemencées par frottis de spores.

Les cultures (10 boîtes de Petri par espèce fongique et par condition) sont placées à $18{ }^{\circ} \mathrm{C}$ avec une photopériode de $16 \mathrm{~h}$ lumière $/ 8 \mathrm{~h}$ obscurité. Après $12 \mathrm{j}$ pour $S$. nodorum et $7 \mathrm{j}$ pour $B$. cinerea, les spores sont recueillies par 3 lavages des colonies avec à chaque fois $10 \mathrm{ml}$ d'eau distillée. Le nombre de spores est 
évalué à l'aide d'une cellule de Thoma. Les résultats sont exprimés en p. 100 du témoin après correction en tenant compte de la surface mycélienne des colonies par rapport à celle du témoin.

\section{G. Influence de $\mathbf{Z n}^{++}$}

L'influence de $\mathrm{Zn}^{++}$sur la sporulation et la croissance des 2 champignons en présence de toxine est examinée par comparaison entre des cultures ayant bénéficié ou non d'un apport de $\mathrm{ZnSO}_{4}, 7 \mathrm{H}_{2} \mathrm{O}$ dans le milieu.

Les cultures sont effectuées en boîtes de Petri sur milieu malt 2 p. 100 avec 2 p. 100 de gélose. Des quantités de $\mathrm{ZnSO}_{4}, 7 \mathrm{H}_{2} \mathrm{O}$ correspondant à des con- centrations finales comprises entre 0,05 et $50 \mathrm{mg} / 1$ sont incorporées au milieu avant la stérilisation.

Seules les désacétylsirodesmine PL et sirodesmine PL ont été étudiées dans ces expériences.

\section{RÉSULTATS}

\section{A. Croissance}

Les sirodesmines PL se montrent assez peu actives sur la croissance linéaire de $S$. nodorum (fïg. 1) ; par contre, la croissance pondérale de ce champignon est fortement affectée par la désacétylsirodesmine $\mathrm{PL}$ ainsi que par la diacétylsirodesmine PL. La sirodesmine PL provoque, quant à elle, un ralentissement de
Légendes des figures 1 à 4

Effet des désacétylsirodesmine (A), sirodesmine $P L(B)$ et diacétylsirodesmine $(C)$, en fonction de leurs concentrations. Résultats exprimés en p. 100 du témoin.

Effect of desacetylsirodesmin $P L(A)$, sirodesmin $P L(B)$ and diacetylsirodesmin $P L(C)$, at different concentrations as a percentage of the control.

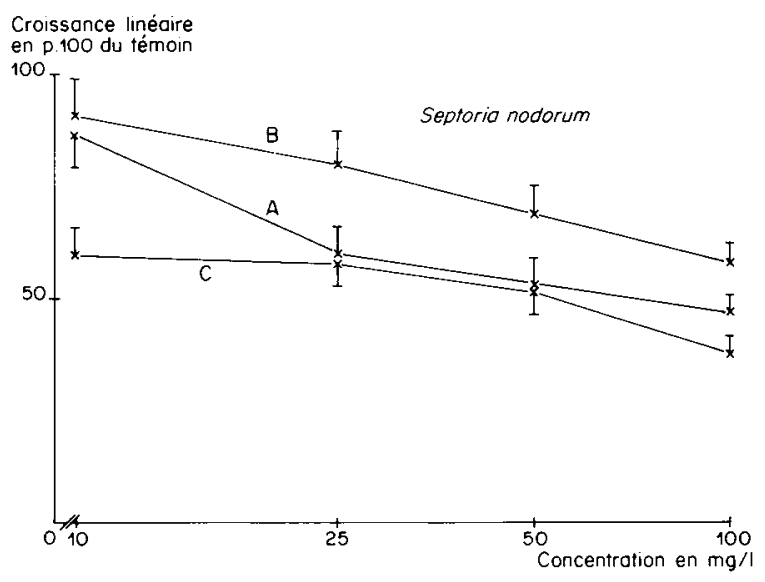

Figure 1

Croissance linéaire de Septoria nodorum. Cultures de $7 \mathrm{j}$ à $18^{\circ} \mathrm{C}$. Linear growth of Septoria nodorum. Incubation at $18{ }^{\circ} \mathrm{C}$ for 7 days.

Croissance linéaire

en $\mathrm{p} .100$ du témoin

100

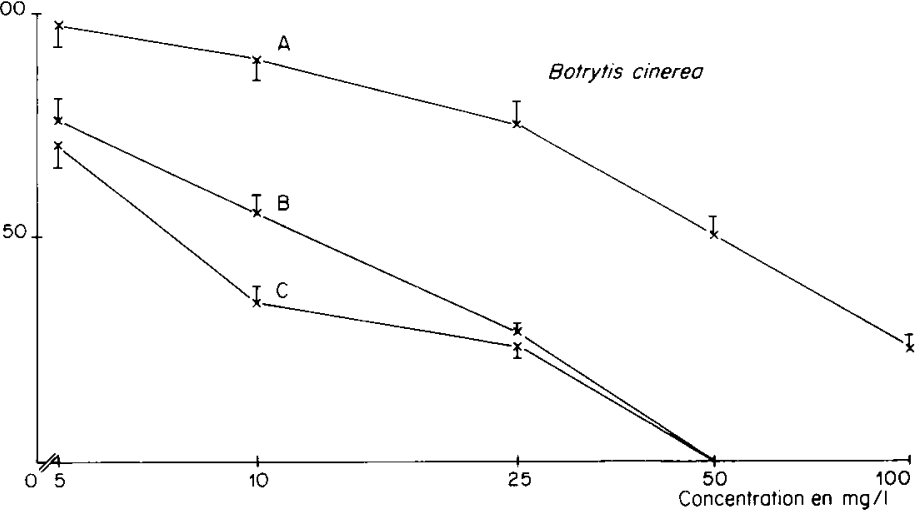

Figure 3

Croissance linéaire de Botrytis cinerea. Cultures de 5 jà $25^{\circ} \mathrm{C}$.

Linear growth of Botrytis cinerea. Incubation at $25^{\circ} \mathrm{C}$ for 5 days.

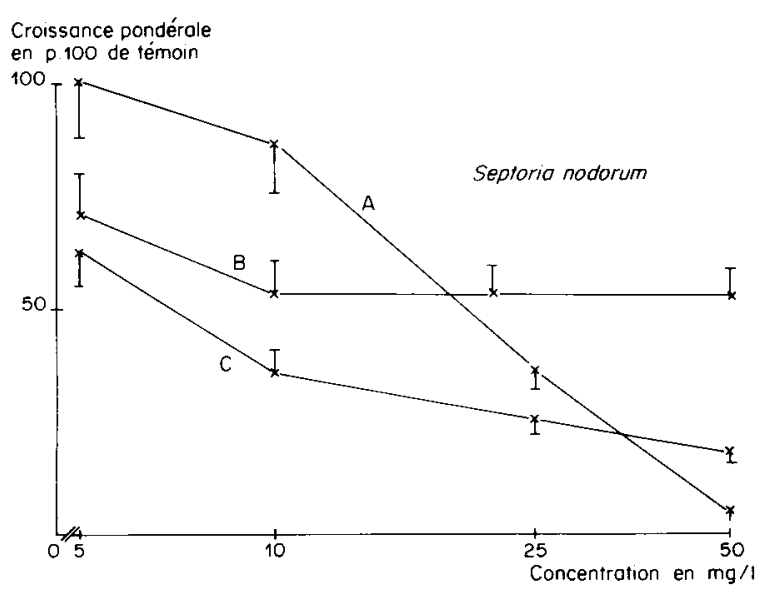

Figure 2

Croissance pondérale de Septoria nodorum. Poids de matière sèche après $7 j$ de culture à $20{ }^{\circ} \mathrm{C}$.

Dry weight of Septoria nodorum. Incubation at $20^{\circ} \mathrm{C}$ for 7 days.

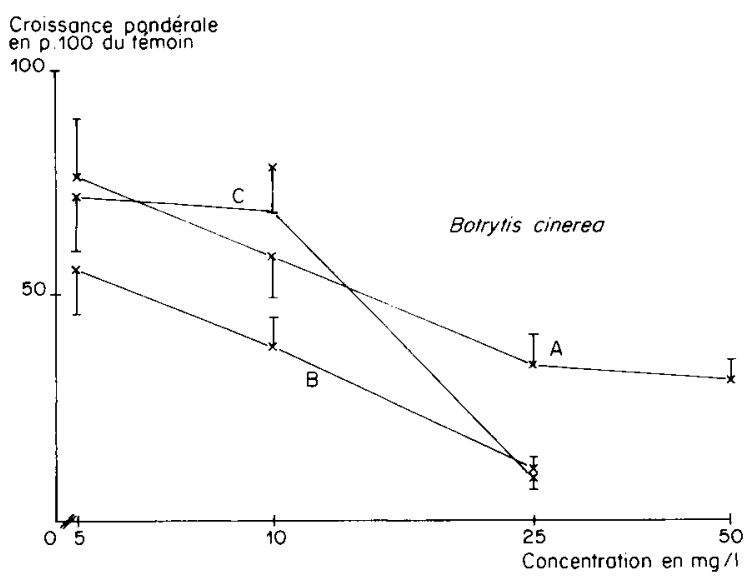

Figure 4

Croissance pondérale de Botrytis cinerea. Poids de matière sèche après $5 j$ de culture à $20^{\circ} \mathrm{C}$.

Dry weight of Botrytis cinerea. Incubation at $20{ }^{\circ} \mathrm{C}$ for 5 days. 
la croissance pondérale qui reste constant à partir de la concentration de $10 \mathrm{mg} / 1$ (fig. 2).

Dans le cas de $B$. cinerea, la désacétylsirodesmine PL se montre moins active que les 2 autres composés, que ce soit sur la croissance linéaire ou sur la croissance pondérale (fig. 3 et 4 ). En règle générale, $B$. cinerea paraît plus sensible que $S$. nodorum vis-àvis des molécules étudiées. Les intervalles de confiance des moyennes ont été déterminés au seuil de 95 p. 100 après transformation logarithmique des diamètres.

L'analyse de variance montre que l'interaction entre les répétitions et les différentes conditions expérimentales est faible par rapport aux effets dose et traitement.

\section{B. Germination des spores}

La germination des spores de $S$. nodorum est peu modifiée en présence des sirodesmines (tabl. 1). Il faut cependant noter un retard dans l'apparition des tubes germinatifs avec la sirodesmine PL et la diacétylsirodesmine PL et un arrêt de croissance des jeunes filaments avec la désacétylsirodesmine PL à la concentration de $100 \mathrm{mg} / \mathrm{l}$.

Dans le cas de $B$. cinerea, la diacétylsirodesmine PL et la sirodesmine PL inhibent la germination des spores contrairement à la désacétylsirodesmine PL qui demeure inactive à des concentrations élevées (tabl. 2). Aucun retard dans l'apparition des tubes germinatifs n'a été observé chez ce champignon.

\section{TABLEAU 1}

Germination des spores de Septoria nodorum. Action des désacétylsirodesmine $P L(A)$, sirodesmine $P L(B)$ et diacétylsirodesmine $P L$ (C) à la dose de $100 \mathrm{mg} / \mathrm{l}$.

Les résultats sont exprimés en p. 100 de spores germées en $24 \mathrm{~h}$ rapporté au taux de germination du témoin.

Spore germination of Septoria nodorum. Effect of desacetylsirodesmin $P L(A)$, sirodesmin $P L(B)$ and diacetylsirodesmin $P L \quad(C)$ at different concentrations as a percentage of the control.

\begin{tabular}{|c|c|c|c|}
\hline $\begin{array}{l}\text { Temps } \\
\text { en } h\end{array}$ & A & B & C \\
\hline 24 & 100 & 75 & 20 \\
\hline 36 & 100 & 100 & 100 \\
\hline
\end{tabular}

\section{Sporulation}

La sporulation de $S$. nodorum est fortement réduite en présence de désacétylsirodesmine PL (tabl. 3). A la concentration de $4 \mathrm{mg} / \mathrm{l}$, dose qui n'affecte pas la croissance mycélienne, le nombre de spores représente environ 1 p. 100 du témoin.

Ce pouvoir anti-sporulant n'est observable qu'à $50 \mathrm{mg} / \mathrm{l}$ dans le cas de la diacétylsirodesmine PL mais est plus réduit ( 31 p. 100 du témoin) et associé à une forte diminution de la croissance mycélienne.

La sirodesmine PL n'agit sur la sporulation de $S$. nodorum qu'à des concentrations très élevées $(200 \mathrm{mg} / \mathrm{l})$; en cas de culture prolongée dans ces conditions ( 3 mois ; $200 \mathrm{mg} / \mathrm{l}$ ) on assiste, chez $S$. nodo-

\section{TABLEAU 2}

Germination des spores de Botrytis cinerea. Action des désacétylsirodesmine $P L(A)$, sirodesmine $P L(B)$ et diacétylsirodesmine $P L$ (C) en fonction de leur concentration.

Les résultats sont exprimés en p. 100 de spores germées en 24 h rapporté au taux de germination du témoin.

Spore germination of Botrytis cinerea. Effect of desacetylsirodesmin $P L(A)$, sirodesmin $P L(B)$ and diacetylsirodesmin $P L(C)$ at different concentrations as a percentage of the control.

\begin{tabular}{lccc}
\hline $\begin{array}{l}\text { Concentration } \\
\text { en mg/l }\end{array}$ & A & B & C \\
\hline 5 & 100 & 96 & 68 \\
\hline 10 & 100 & 75 & 30 \\
\hline 75 & 100 & 25 & 3 \\
\hline 100 & 100 & 4 & 1 \\
\hline 150 & 100 & 0 & 0 \\
\hline 200 & 90 & 0 & 0 \\
\hline \hline
\end{tabular}

TABLEAU 3

Sporulation de Septoria nodorum. Action des désacétylsirodesmine $P L(A)$, sirodesmine $P L(B)$ et diacétylsirodesmine $P L(C)$ en fonction de leur concentration.

Les résultats sont exprimés en $p .100$ du nombre de spores observé chez le témoin.

Sporulation of Septoria nodorum. Effect of desacetylsirodesmin $P L$ (A), sirodesmin $P L(B)$ and diacetylsirodesmin $P L(C)$ at different concentrations as a percentage of the control.

\begin{tabular}{lccc}
\hline $\begin{array}{l}\text { Concentration } \\
\text { en } \mathrm{mg} / 1\end{array}$ & A & B & C \\
\hline 2 & 50 & 100 & 100 \\
\hline 4 & 1 & 100 & 100 \\
\hline 6 & 0 & 100 & 100 \\
\hline 50 & 0 & 108 & 31 \\
\hline
\end{tabular}

rum, à une perte irréversible du pouvoir sporulant ; contrairement à la croissance, la sporulation n'est pas rétablie si le champignon est replacé sur un milieu témoin ou même enrichi en $\mathrm{ZnSO}_{4}$.

Parallèlement à l'inhibition de la sporulation, on observe, dans tous les cas, la disparition d'une pigmentation brune du milieu de culture aux abords des colonies mycéliennes.

L'effet anti-sporulant de la désacétylsirodesmine PL est également observé chez $B$. cinerea (tabl. 4) il s'avère cependant moins important que chez $S$. nodorum : $10 \mathrm{mg} / 1$ réduisent à $22 \mathrm{p} .100$ le nombre de spores par rapport au témoin et il faut atteindre une concentration de $100 \mathrm{mg} / 1$ pour n'obtenir qu'l p. $100 \mathrm{du}$ témoin. Des effets similaires sont observés avec la sirodesmine PL et la diacétylsirodesmine PL mais ils sont alors associés à une très forte diminution de la croissance mycélienne.

\section{Action de $\mathrm{Zn}^{++}$}

L'inhibition de la sporulation et de la croissance de $S$. nodorum observée avec la désacétylsirodesmine 
TABLEAU 4

Sporulation de Botrytis cinerea. Action des désacétylsirodesmine $P L$ $(A)$, sirodesmine $P L(B)$ et diacétylsirodesmine $P L(C)$ en fonction de leur concentration.

Les résultats sont exprimés en p. $100 \mathrm{du}$ nombre de spores observé chez le témoin.

Sporulation of Botrytis cinerea. Effect of desacetylsirodesmine $P L$ $(A)$, sirodesmine $P L(B)$ and diacetylsirodesmine $P L(C)$ at different concentrations as a percentage of the control.

\begin{tabular}{lccc}
\hline $\begin{array}{l}\text { Concentration } \\
\text { en mg/l }\end{array}$ & A & B & C \\
\hline 5 & 86 & 78 & 97 \\
\hline 10 & 22 & 20 & 28 \\
\hline 25 & 7 & 3 & 13 \\
\hline 50 & 3 & $<1$ & 7 \\
\hline 100 & 1 & 0 & 3 \\
\hline \hline
\end{tabular}

PL est levée par l'addition de $\mathrm{ZnSO}_{4}, 7 \mathrm{H}_{2} \mathrm{O}$ dans le milieu de culture. Ce phénomène est fonction des doses utilisées par rapport aux concentrations de toxine (fig. 5). Cependant, dans le cas de la sirodesmine PL qui n'agit pas sur la sporulation du champignon, l'inhibition de la croissance n'est pas levée.

Pour $B$. cinerea, l'addition de $\mathrm{ZnSO}_{4}, \quad 7 \mathrm{H}_{2} \mathrm{O}$ annule également l'effet antisporulant de la désacétylsirodesmine PL et de la sirodesmine PL ; en revanche, aucun effet comparable n'est observé sur la croissance mycélienne (fig. 5). Il a été vérifié que l'incorporation de $\mathrm{ZnSO}_{4}, 7 \mathrm{H}_{2} \mathrm{O}$ dans le milieu de culture exempt de toxine ne modifie pas de façon sensible, aux concentrations utilisées, la croissance et la sporulation des 2 champignons.

\section{DISCUSSION ET CONCLUSION}

Les résultats obtenus dans cette étude mettent en évidence les propriétés fongitoxiques des sirodesmines PL, tant au niveau de la croissance des champignons qu'à celui de leur reproduction. Ils permettent également de confirmer l'importance de la structure fonctionnelle d'une molécule vis-à-vis de ses activités biologiques.

Dans le cas des sirodesmines PL, la présence ou l'absence de fonctions alcool libres jouent bien évidemment un rôle sur la solubilité des composés mais également sur leur pénétration à travers les membranes et sur leur devenir au sein de l'organisme.

La désacétylsirodesmine $\mathrm{PL}$, composé possédant 3 fonctions alcool libres, présente une activité antisporulante importante vis-à-vis de $S$. nodorum et de $B$. cinerea; cette action obtenue avec de faibles concentrations de toxine est indépendante de l'effet observé sur la croissance mycélienne. La désacétylsirodesmine PL est inactive sur la germination des spores des 2 champignons.

Avec la sirodesmine PL, analogue naturel possédant 2 fonctions alcool libres, l'action antisporulante n'apparaît que chez $B$. cinerea mais est associée à une forte réduction de la croissance mycélienne. De même,
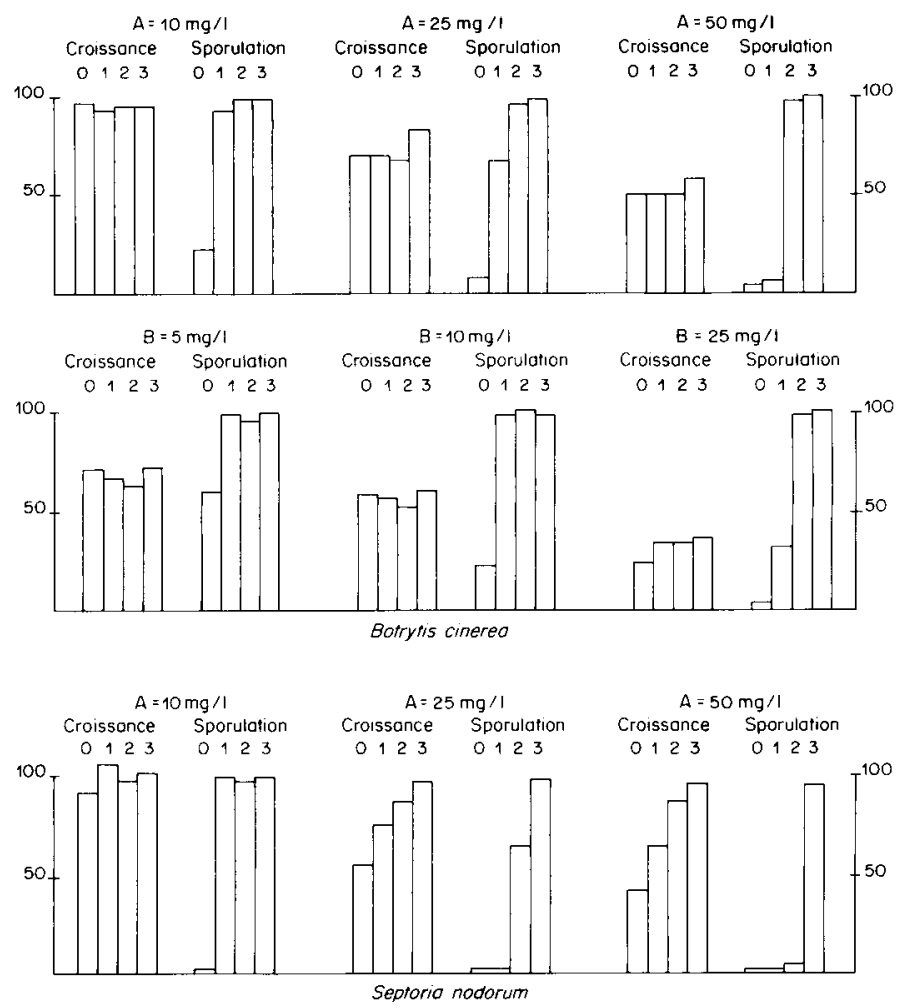

Figure 5

Croissance linéaire et sporulation de $\mathrm{B}$. cinerea et $\mathrm{S}$. nodorum. Action antagoniste de $\mathrm{Zn}^{++}$vis-à-vis de la désacétylsirodesmine $P L$ (A) et de la sirodesmine $P L(B)$.

Linear growth and spore formation by $\mathbf{B}$. cinerea and $\mathrm{S}$. nodorum. Antagonistic action of $\mathrm{Zn}^{++}$with desacetylsirodesmin $P L(A)$ and sirodesmin $P L(B)$ at different concentrations as a percentage of the control.

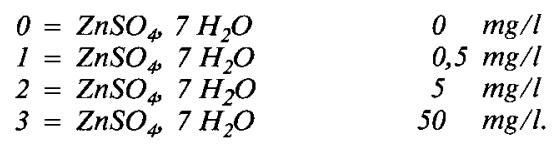

Résultats exprimés en p. 100 du témoin.

S. nodorum croissance: cultures de 5 j à $18{ }^{\circ} \mathrm{C}$. Photopériode lumière $16 \mathrm{~h}$; sporulation: cultures de $7 \mathrm{j}$ à $18{ }^{\circ} \mathrm{C}$. Photopériode lumière $16 \mathrm{~h}$.

B. cinerea sporulation: cultures de 12 j à $18^{\circ} \mathrm{C}$. Photopériode lumiere $16 \mathrm{~h}$.

seule la germination des spores de ce champignon est inhibée par le composé alors que, chez S. nodorum, elle est simplement ralentie.

Le $3^{\text {e }}$ composé moins hydroxylé, la diacétylsirodesmine PL, agit sur la sporulation de $S$. nodorum et de $B$. cinerea d'une manière non spécifique car également associée à un effet prononcé sur la croissance mycélienne. Son action sur la germination des spores est identique à celle observée avec la sirodesmine PL.

L'action antagoniste de $\mathrm{Zn}^{++}$vis-à-vis des sirodesmines PL se manifeste au niveau de la sporulation et, seulement dans certains cas, sur la croissance linéaire. Cette protection par $\mathrm{Zn}^{++}$a pu être également observée au niveau de l'activité phytotoxique sur des germinations de graines de colza. En effet, à la concentration de $25 \mathrm{mg} / \mathrm{l}$, les désacétylsirodesmine PL et sirodesmine PL bloquent totalement la croissance des radicules de colza en provoquant leur nécrose. L'addition de $50 \mathrm{mg} / \mathrm{l}$ de $\mathrm{ZnSO}_{4}, 7 \mathrm{H}_{2} \mathrm{O}$, lève cette inhibition; des doses inférieures $(0,5$ et $5 \mathrm{mg} / \mathrm{l})$ ne sont cependant pas actives (B. POIRET, résult. non publiés, 1983). 
Des essais similaires effectués sur champignons et sur graines avec $\mathrm{FeSO}_{4}, \mathrm{MnSO}_{4}$ et $\mathrm{MgSO}_{4}$ dans les mêmes conditions se sont montrés négatifs (B. POIRET, résult. non publiés, 1983).

Cette action de $\mathrm{Zn}^{++}$a déjà été observée en pathologie animale vis-à-vis des sporidesmines, molécules voisines de sirodesmines et qui ont une forte toxicité chez différents animaux (SMITH et al., 1977 ; TOWERS, 1977 ; TOWERS \& SMITH, 1978), mais le mode d'action de cet ion métallique reste cependant méconnu.

Des analyses spectrométriques préliminaires en RMN du ${ }^{13} \mathrm{C}$ n'ayant pas pu mettre en évidence la formation d'un complexe $\mathrm{Zn}^{++} /$sirodesmines $\mathrm{PL}$ (M. DevYs, comm. pers., 1983), il est possible d'envisager un phénomène de compétition entre ces 2 éléments au niveau d'un même "site biochimique " intéressant, entre autres, la sporulation des champignons.

De nombreux auteurs ont montré l'importance de $\mathrm{Zn}^{++}$sur le métabolisme des champignons $(\mathrm{COCH}-$ RANE, 1958 ; WOLD \& SUZUKI, 1976) ; toutefois son intervention dans les mécanismes de la sporulation n'apparaît pas très nettement. FOSTER (1939) constate que la sporulation d'Aspergillus niger Van Tiegh. est partiellement inhibée par l'addition de $\mathrm{Zn}^{++}$au milieu de culture alors que la formation des conidies de Fusarium oxysporum Schlecht. est stimulée en présence de $\mathrm{Zn}^{++}$à la concentration de $50 \mathrm{mg} / \mathrm{l}$.

On connaît depuis longtemps l'importance de $\mathrm{Zn}^{++}$ dans les phénomènes biologiques. Plusieurs auteurs ont en particulier mis en évidence le rôle de cet élément au cours de la synthèse d'ARN : SCRUTTON et al. (1971) ont montré la présence de $\mathrm{Zn}^{++}$chez l'enzyme RNA polymérase de Escherichia coli, alors que TERHUNE \& SANSTEAD (1972) ont précisé son rôle dans des activités RNA polymérasiques chez des mammifères.

Chez les champignons, WEGENER \& ROMANO (1963) ont démontré l'action stimulante de $\mathrm{Zn}^{++}$sur la formation d'ARN et sur la synthèse protéique de Rhizopus nigricans Ehr., cependant que WACKER \& VALLÉE (1959), ayant mis en évidence des molécules de zinc associées avec des ARN de diverses sources, ont avancé l'hypothèse d'un rôle important joué par ce métal dans le maintien de la stabilité configurationnelle des molécules d'ARN.

Actuellement, l'ensemble des données bibliographiques conduit à penser que l'action des épipolythiopipérazinediones se situe au niveau de la synthèse d'ARN (FEREZOU, 1981). Ces observations, associées à la mise en évidence dans notre étude d'une action antagoniste de $\mathrm{Zn}^{++}$vis-à-vis de molécules possédant un effet antisporulant, laissent entrevoir une voie d'accès dans l'explication du mécanisme complexe et encore peu connu de la sporulation des micromycètes.

Reçu le 20 septembre 1984. Accepté le 8 février 1985.

\section{RÉFÉRENCES BIBLIOGRAPHIQUES}

Bousquet J. F., Ferezou J. P., Devys M., Barbier M., 1977. Sur une toxine produite par le champignon Phoma lingam Tode, parasite du Colza : isolement et propriétés. C. R. Acad. Sci. Paris, sér. D, 284, 927-928.

Cochrane J. W., 1958. Physiology of Fungi. John Wiley and Sons NY London.

Ferezou J. P., Quesneau-Thierry A., Pascard-Billy C., Barbier M., Bousquet J. F., Boudart G., 1977. Structure de deux toxines isolées des cultures de Phoma lingam Tode : la sirodesmine PL et la désacétylsirodesmine PL. Nouv. J. Chim., 1, 327-334.

Ferezou J. P., 1981. Piperazinediones soufrées et non soufrées produites par le champignon phytopathogène Phoma lingam Tode: étude chimique et biosynthétique. Thèse Doct. Sci. nat., Fac. Sci. Univ. Paris-Sud, 165 p.

Foster J. W., 1939. The heavy metal nutrition of fungi. Bot. Rev., V (4), 207-239.

Scrutton M. C., Wu C. W., Goldwait D. A., 1971. The presence and possible role of zinc in RNA polymerase obtained from Escherichia coli. Proc. Nat. Acad. Sci. U.S.A., 68, 2497.

Smith B. L., Embling P. P., Towers N. R., Wright D. E., \& Payne E., 1977. The protective effect of zinc sulphate in experimental sporidesmin poisoning of sheep. $N . Z$. Vet. J., 25, 124-127.
Taylor A., 1971. The toxicology of sporidesmins and other epipolythioxopiperazines, 337-376. In Kadis A., Ciegler A., AJL S. J. "Microbial Toxins ", Acad. Press, NY, Vol. 7.

Terhune M. W., Sandstead H. H., 1972. Decreased RNA polymerase activity in zinc deficiency. Science, 177, 68-69.

Towers N. R., 1977. Effect of zinc on the toxicity of the mycotoxin sporidesmin to the rat. Life Sci, 20, 413-418.

Towers N. R., Smith B. L., 1978. The protective effect of zinc sulphate in experimental sporidesmin intoxication of lactating dairy cows. N. Z. Vet. J., 26, 199-202.

Wacker W. E. C., Vallée B. L., 1959. Nucleic acids and metals. I Chromium, manganese, nickel, iron and other metals in ribonucleic acid from diverse biological sources. J. Biol. Chem., 234, 32573262 .

Wegener W. S., Romano A. H., 1963. Zinc stimulation of RNA and protein synthesis in Rhizopus nigricans. Science, 142, 16691670

Wold W. S. M., Suzuki I., 1976. The citric acid fermentation by Aspergillus niger : regulation by zinc of growth and acidogenesis. Can. J. Microbiol., 22, 1083-1092. 